\title{
Conformational Stability, TGA, and Molecular Docking Investigations of p-Coumaric Acid with Special Relevance to Anti-Cancer and Antibacterial Activity
}

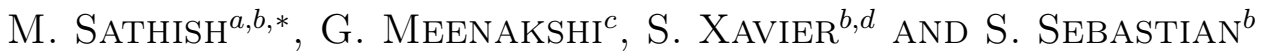 \\ ${ }^{a}$ Research Scholar, Manonmaniam Sundaranar University, Thirunelveli 627012, India \\ ${ }^{b}$ Department of Physics, St. Joseph's College of Arts and Science (Autonomous), \\ Cuddalore, Tamilnadu 607 001, India \\ ${ }^{c}$ Department of Physics, Kanchi Mamunivar Center for Post Graduate Studies and Research, \\ Lawspet, Puducherry 605 008, India \\ ${ }^{d}$ Research Scholar, Bharathiyar University, Coimbatore, India \\ (Received September 10, 2016; in final form March 22, 2017)
}

\begin{abstract}
In this work an attempt is made to analysis of the possible different conformers of p-coumaric acid (PCA) by using density functional method. The total energy of four possible conformers were calculated by using B3LYP $/ 6$ $311 \mathrm{G}(\mathrm{d}, \mathrm{p})$ method. Computational result identifies that the most stable conformer of PCA is C2. The formation of inter- and intra-molecular hydrogen bonding between $-\mathrm{OH}$ and $-\mathrm{COOH}$ group gave the evidence for dimer formation for PCA molecule. The highest occupied-lowest unoccupied molecular orbital analysis shows that the negative electrostatic region situated over the $-\mathrm{COOH}$ group and positive electrostatic potential region are localized on ring system and all hydrogen. The PCA has been screened to anti-microbial activity and found to exhibit antibacterial effects. Molecular docking results suggest that PCA may exhibit inhibitory activity against lung cancer protein and may act as potential against lung cancer.
\end{abstract}

DOI: 10.12693/APhysPolA.131.1512

PACS/topics: conformational analysis, molecular geometry, molecular docking, p-coumaric acid, hydrogen bonding, TGA

\section{Introduction}

The phenolic acids have various biological activities in the human body. It helps us to search free radicals, chelate metal ions and induce changes in enzyme activity and protein availability. Recent studies have confirmed that phenolic acid prevent coronary heart disease, cancer, inflammation, and diabetes. Hydroxycinnamic acid and its derivatives (e.g., coumaric, caffeic, ferulic and sinapic acids) are important pharmaceuticals molecules used as drugs for high blood pressure, stroke prevention, and possess antitumor activity [1-3]. There are three possible isomers of coumaric acid which differ in the position of the hydroxyl group substitution on the phenyl group. Normally coumaric acids can be found in cereals, fruits, legumes, nuts, vegetables, oilseeds, red wine, beer and tea [4]. Also, p-coumaric acid is abundantly present in pineapple. It has been found to reduce the risk of stomach cancer [5] by reducing the formation of carcinogenic nitrosamines [6]. Based on the above literature data only few studies have been carried out for PCA molecule. Molecular structure and the Fourier transform infrared (FT-IR) and FT-Raman spectroscopic studies combined with theoretical approach on co-crystal of ionized with p-coumaric acid were studied by Ravikumar et al. [7].

*corresponding author; e-mail: sathishmary2013@gmail.com
Sadowy et al. [8] reported the spectroscopic and NMR studies of trans p-coumaric acid and alkali metal coumaric acid. Recently structural, thermal and quantum chemical analysis of p-coumaric and caffeic acids has been done by Kumar et al. [9]. The optimized structures of these acids were verified by density functional theory (DFT) approach. Conformational, vibrational and charge transfer study of cis-2-methoxycinnamic acid were carried out by Arjunan et al. [10]. Garzón et al. [11] and Giacomelli et al. [12] have made study on reactivity of the molecule with oxygen species and antioxidant activity of the molecule. By going through the literature survey, we noticed that there are some theoretical calculations carried out and reported [11, 12], however a sharp analysis and comparison with the theoretical data have not yet been made on PCA molecule. Our present aim is to study the experimental and theoretical studies of PCA molecule.

\section{Experimental details}

\subsection{UV-vis and thermo gravity measurements}

The PCA molecule has been purchased from Sigma Aldrich Chemicals, USA. The UV-visible absorption spectrum of PCA was examined in the range 200$800 \mathrm{~nm}$ using Shimadzu UV-1650 PC, UV-vis spectrometer. The UV-vis pattern was taken from a $10^{-5}$ molar solution of PCA, dissolved in ethanol and shown in Fig. 1. The thermo gravimetry analysis (TGA) was done by thermogravity instrument SDT Q600V20.9 Build 20 as shown in Fig. 1. 

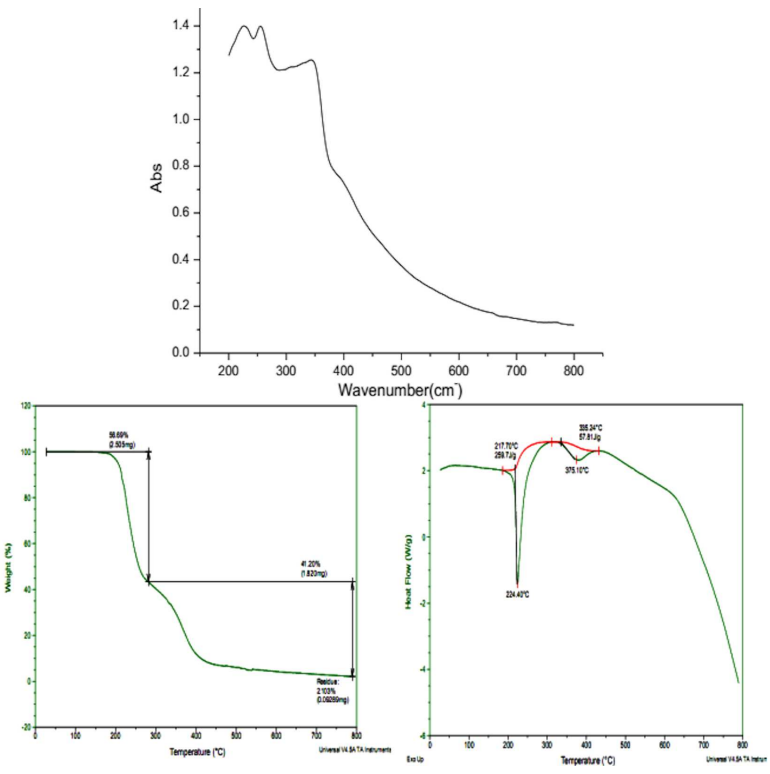

Fig. 1. Recorded UV-vis (top) and TGA (bottom) spectrum of p-coumaric acid.

\subsection{Computational details}

The optimized geometry of PCA were calculated by Gaussian 09W program package [13]. The basis set 6$311 \mathrm{G}(\mathrm{d}, \mathrm{p})$ augmented by "d" polarization function on heavy atom and "p" polarization function on hydrogen atoms were used for better description of polar bonds of molecules $[14,15]$. The UV-vis spectrum, electronic transitions, vertical excitation energies and oscillator strength were computed with time dependent DFT (TD-DFT) method $[16,17]$.

\section{Results and discussion}

\subsection{Molecular geometry}

The four conformer energies are shown in Fig. 2, geometric parameters, namely bond length, and bond angles for the most stable conformer of PCA molecule, were computed by B3LYP/6-311G(d,p) method and presented in Tables I and II, the atom numbering scheme adopted for PCA molecule for monomer is in Fig. 2. PCA molecule has become of great interest due to two substituents in the ring system (i.e. hydroxyl and carboxyl groups). The molecule PCA under investigation has four different conformations. First our aim to calculate the most stable conformer by finding lowest energy for each conformer, we noticed that $\mathrm{C} 2(E=-573.60618630$ a.u. $)$ is most stable conformer when compared to others as evident from Fig. 2 by B3LYP/6-311G(d,p) method. The stable conformer structure is having intramolecular $(\mathrm{O} \ldots \mathrm{H})$ bonding between the two COOH groups. The least stable conformer is obtained for C3 $(E=-573.60486664$ a.u.) as shown in Fig. 2. By B3LYP/6-311G(d,p) method by going through the literature survey there is no XRD data available for PCA molecule so far. In this present study we compare XRD data of 2-coumaric acid [18] and 3 -coumaric acid [19] presented in Table I. The intermolecular interaction is formed by $-\mathrm{COOH}$ group of $\mathrm{PCA}$ molecule which forms a dimer and intramolecular interaction $\mathrm{O}-\mathrm{H}$. . . O connecting the adjacent dimers leading to infinite chain in random directions.

TABLE I

Geometrical parameters optimized in trans-conformers of p-coumaric acid (bond length $[\AA]$, bond angle $\left[{ }^{\circ}\right]$ ).

\begin{tabular}{|c|c|c|c|c|}
\hline \multirow[t]{2}{*}{ Parameters } & \multicolumn{2}{|c|}{ B3LYP/6-311G(d,p) } & \multicolumn{2}{|c|}{${ }^{a}$ Exp. X-ray data } \\
\hline & monomer & dimer & monomer & dimer \\
\hline \multicolumn{5}{|c|}{ Bond length $[\AA \AA]$} \\
\hline $\mathrm{C} 1-\mathrm{C} 2$ & 1.403 & 1.403 & 1.401 & $1.402(4)$ \\
\hline $\mathrm{C} 1-\mathrm{C} 6$ & 1.409 & 1.409 & 1.394 & $1.395(4)$ \\
\hline C1-C13 & 1.457 & 1.457 & 1.466 & $1.446(4)$ \\
\hline $\mathrm{C} 2-\mathrm{C} 3$ & 1.389 & 1.389 & 1.389 & $1.386(4)$ \\
\hline $\mathrm{C} 2-\mathrm{H} 7$ & 1.085 & 1.085 & - & \\
\hline $\mathrm{C} 3-\mathrm{C} 4$ & 1.396 & 1.396 & 1.368 & \\
\hline $\mathrm{C} 3-\mathrm{H} 8$ & 1.086 & 1.086 & 0.908 & \\
\hline $\mathrm{C} 4-\mathrm{C} 5$ & 1.401 & 1.401 & 1.379 & $1.379(5)$ \\
\hline C4-O11 & 1.360 & 1.361 & - & \\
\hline $\mathrm{C} 5-\mathrm{C} 6$ & 1.382 & 1.382 & 1.379 & \\
\hline C5-H9 & 1.083 & 1.083 & 0.917 & \\
\hline C6-H10 & 1.083 & 1.083 & 1.082 & \\
\hline O11-H12 & 0.963 & 0.963 & - & \\
\hline C13-H14 & 1.088 & 1.087 & 0.613 & \\
\hline C13-C15 & 1.344 & 1.344 & 1.337 & $1.337(5)$ \\
\hline $\mathrm{C} 15-\mathrm{H} 16$ & 1.083 & 1.083 & 1.059 & \\
\hline $\mathrm{C} 15-\mathrm{C} 17$ & 1.471 & 1.470 & 1.460 & $1.460(5)$ \\
\hline $\mathrm{C} 17-\mathrm{O} 18$ & 1.211 & 1.232 & 1.229 & \\
\hline C17-O19 & 1.360 & 1.323 & 1.329 & \\
\hline O19-H20 & 0.968 & 1.000 & 0.987 & \\
\hline \multicolumn{5}{|c|}{ Bond angle $\left[^{\circ}\right]$} \\
\hline $\mathrm{C} 2-\mathrm{C} 1-\mathrm{C} 6$ & 117.55 & 117.54 & 118.21 & $118.7(3)$ \\
\hline $\mathrm{C} 1-\mathrm{C} 2-\mathrm{C} 3$ & 121.58 & 121.61 & 120.59 & $120.6(3)$ \\
\hline $\mathrm{C} 3-\mathrm{C} 4-\mathrm{C} 5$ & 119.73 & 119.72 & 120.41 & $120.4(3)$ \\
\hline $\mathrm{C} 1-\mathrm{C} 6-\mathrm{C} 5$ & 121.44 & 121.42 & 120.59 & $120.6(3)$ \\
\hline
\end{tabular}

${ }^{a}$ Taken from Refs. $[16,17]$

TABLE II

Intermolecular hydrogen bonding parameters based on B3LYP /6-311G(d,p) method (bond length $[\AA]$, bond angle $\left[{ }^{\circ}\right]$ and dihedral angle $\left.\left[{ }^{\circ}\right]\right)$.

\begin{tabular}{c|c|c|c}
\hline \hline \multicolumn{4}{c}{$\mathrm{O} 19-\mathrm{H} 20 \ldots \mathrm{O} 36$} \\
\hline O19-H20 & $\mathrm{H} 20 \ldots \mathrm{O} 36$ & $\mathrm{O} 19 \ldots \mathrm{O} 36$ & $\mathrm{O} 19-\mathrm{H} 20 \ldots \mathrm{O} 36$ \\
1.000 & 1.6556 & 2.6560 & $179.83^{\circ}$ \\
\hline \multicolumn{4}{c}{$\mathrm{O} 37-\mathrm{H} 38 \ldots \mathrm{O} 18$} \\
\hline O37-H38 & $\mathrm{H} 38 \ldots \mathrm{O} 18$ & $\mathrm{O} 37 \ldots \mathrm{O} 18$ & $\mathrm{O} 37-\mathrm{H} 38 \ldots \mathrm{O} 18$ \\
1.000 & 1.6496 & 2.6499 & $179.41^{\circ}$
\end{tabular}

The optimized minimum energy of $\mathrm{C} 2$ monomer is 573.60618630 a.u. and dimer is -1147.24104184 a.u. by B3LYP $/ 6-311 G(d, p)$ method. The interaction between 

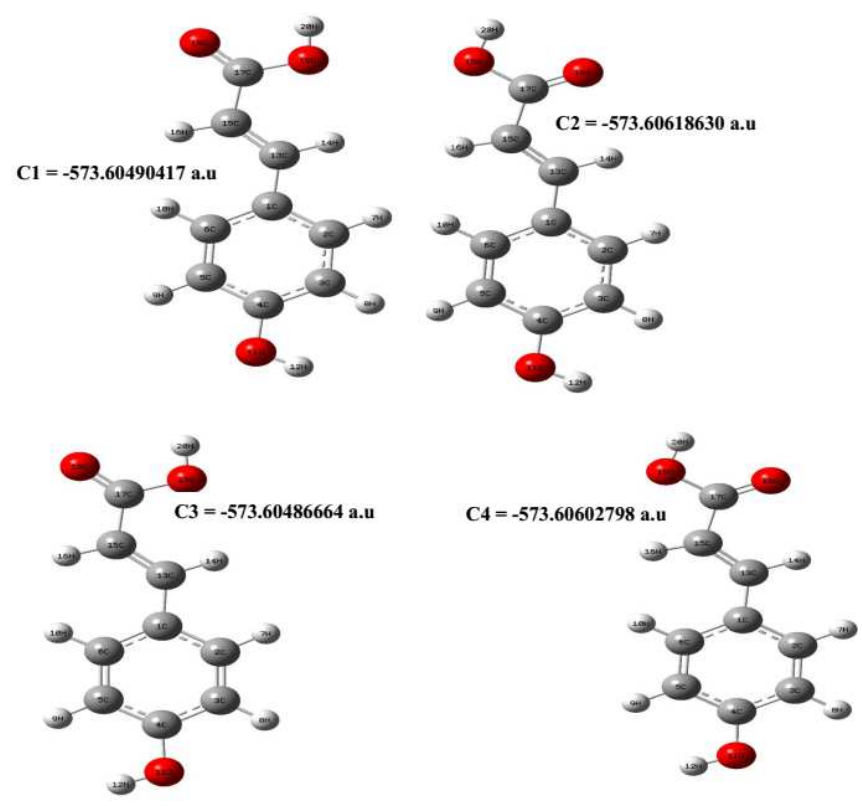

Fig. 2. Different possible conformers of p-coumaric acid.

the two equivalent hydrogen bond i.e. $\mathrm{C}=\mathrm{O} \ldots \mathrm{H}$ contacts, show increase of $\mathrm{O}-\mathrm{H}$ bond length which may involve inter molecular hydrogen bond as evident from lengthened of 0.032 Aupon dimerization. The aromatic ring appears to be little bit distorted as evident from computed bond lengths $\mathrm{C} 1-\mathrm{C} 2, \mathrm{C} 1-\mathrm{C} 6, \mathrm{C} 3-\mathrm{C} 4$ and $\mathrm{C} 4-$ C5 next to the substitution place $(\approx 1.40 \AA)$ longer than the bonds C2-C3 (1.389 $\AA$ ) and C5-C6 (1.382 $\AA$ ) for monomer and dimer respectively are shown in Table I. These distortions are explained in terms of difference in hybridization affected by the substituent at the carbon place to which it is attached. The increase of the $\mathrm{C}-\mathrm{C}$ bond lengths adjacent to the $\mathrm{C} 1-\mathrm{C} 13$ and $\mathrm{C} 4-\mathrm{O} 11$ bonds in the substitution place is accompanied by slightly irregular hexagonal structure of angles C2-C1-C6, C3-C4-C5 which are $117.55^{\circ}, 119.73^{\circ}$ and also evident from $\mathrm{C} 1-$ C2-C3 and $\mathrm{C} 1-\mathrm{C} 6-\mathrm{C} 5$ which are found to be $121.58^{\circ}$ and $121.44^{\circ}$, respectively, by B3LYP $/ 6-311 \mathrm{G}(\mathrm{d}, \mathrm{p})$ method. The deviation noticed between the computed and $\mathrm{XRD}$ geometrical parameters is due to fact that isolated molecule is assumed in theoretical calculation but packing molecule is treated in condensed phase during experimental measurements.

\subsection{Potential energy surface scan study}

Potential energy surface (PES) scan studies were carried out on PCA molecule to achieve the reliable stable conformation among the dihedral angle for $\mathrm{COOH}$ and $\mathrm{OH}$ group. The obtained profile of PES for torsion angle C5-C4-O11-H12 and $\mathrm{H} 14-\mathrm{C} 13-\mathrm{C} 15-\mathrm{C} 17$ are illustrated in Fig. 3. In PCA molecule $\mathrm{COOH}$ and $\mathrm{OH}$ group are also the rotatable coordinate or conformational flexibility within the molecule. During the calculation C5C4-O11-H12 and H14-C13-C15-C17 dihedral angle are varied from $0^{\circ}$ to $360^{\circ}$ for $\mathrm{PCA}$ molecule. We found that for both rotation two minimum energy at $0^{\circ}$ and $360^{\circ}$ of energy of -537.607 a.u. are obtained which implies $\mathrm{C}=\mathrm{O}$ in $\mathrm{COOH}$ and $\mathrm{OH}$ group are inclined in same directional orientation, the PES study also confirm that C2 conformer has more stable structure when compared to other conformers.

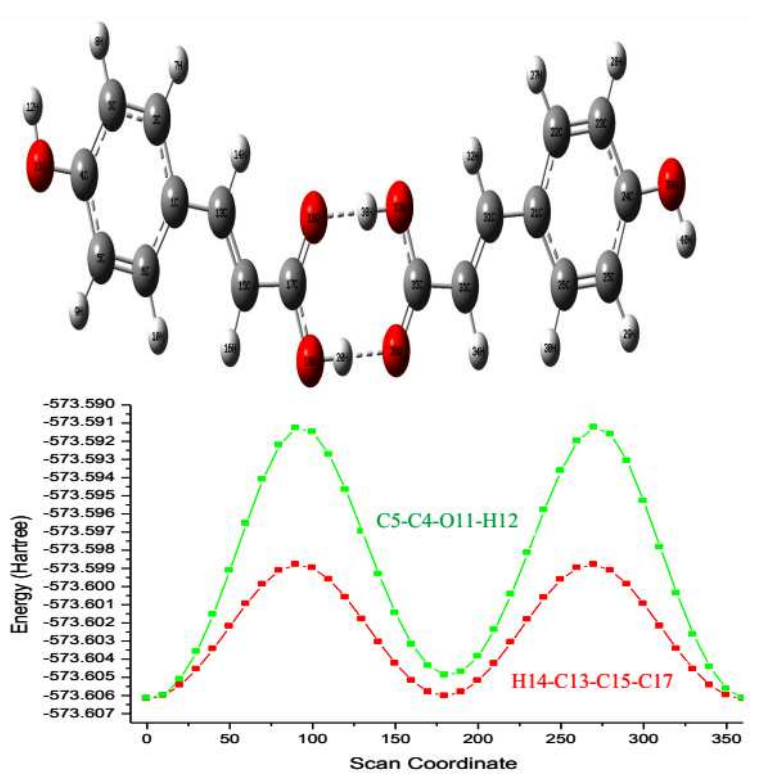

Fig. 3. Dimer structure of p-coumaric acid (top) and potential energy surface diagram of p-coumaric acid (bottom).

\subsection{Frontier molecular orbital analysis}

By knowing the highest occupied molecular orbital (HOMO) and lowest unoccupied molecular orbital (LUMO) we can analyse the chemical reactivity of the molecule. Simply HOMO energy represents how much the molecule could donate electron and LUMO energy indicates how much the electron can accept, by knowing the two values we can determine the stability of the molecule. The study is useful for the chemists in terms of quantum computation $[20,21]$ or in other words the electronic absorption corresponds to the transition from ground to first excited state by one electron excitation from HOMO $\rightarrow$ LUMO. The HOMO is present in the ring system and $\mathrm{HOMO} \rightarrow$ LUMO transition denotes the electron density will transfer from ring system to $\mathrm{COOH}$ group as shown in Fig. 4. The GaussSum2.2 Program [22] is used to illustrate the group contribution of molecular orbitals as shown in Fig. 4.

The HOMO energy of PCA is $-6.23 \mathrm{eV}$ and LUMO energy is $-1.88 \mathrm{eV}$. The energy difference between HOMO and LUMO describes the band gap for PCA. The band gap between HOMO and LUMO is around $4.35 \mathrm{eV}$ which represents eventual charge transfer of electrons in the molecule. HOMO and LUMO energy values are also used to find electronegativity, global chemical reactivity descriptors as hardness, chemical potential, and electrophilicity index [23]. 


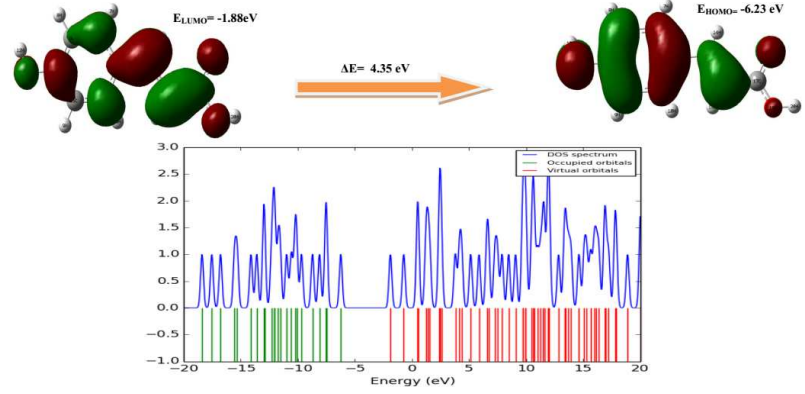

Fig. 4. The atomic orbital compositions of the frontier molecular orbital for p-coumaric acid (top) and density of state (DOS) spectrum of p-coumaric acid (bottom).

To understand the various concepts of pharmacological characteristic of the molecule, several chemical reactivity descriptors are computed by using HOMO and LUMO energies, the ionization energy and electron affinity can be $I=-E_{\mathrm{HOMO}}=6.23 \mathrm{eV}$ and $A=-E_{\mathrm{LUMO}}=$ $1.88 \mathrm{eV}[24]$. The chemical hardness $\eta$ and chemical potential $\mu$ can be calculated by the relation $\eta=(1-A) / 2=$ 2.1755 and $\mu=(-I+A) / 2=-4.055, \chi=(I+A) / 2$ where $A$ and $I$ are called as first ionization potential and electron affinity of the molecule [25] and are tabulated in Table III. Urbaniak et al. [26] have found the HOMOLUMO energy gap of cis-trans ferolic acid in the ethanol phase to be $3.9-4.1 \mathrm{eV}$. The values reveal the antioxidant character of the molecule. The values computed by the authors are well in line with the results of the PCA molecule.

TABLE III

Calculated different energy $[\mathrm{eV}]$ values for PCA molecule.

\begin{tabular}{c|c}
\hline \hline B3LYP $/ 6-311 G(\mathrm{~d}, \mathrm{p})$ & Energy \\
\hline$E_{\text {tot }}$ [Hartree & -573.604904 \\
$E_{\mathrm{HOMO}}$ & -6.23 \\
$E_{\mathrm{LUMO}}$ & -1.88 \\
$E_{\mathrm{HOMO}}-E_{\mathrm{LUMO}}$ gap & 4.53 \\
$E_{\mathrm{HOMO}-1}$ & -7.5 \\
$E_{\mathrm{LUMO}+1}$ & -0.71 \\
$E_{\mathrm{HOMO}-1}-E_{\mathrm{LUMO}+1}$ gap & 6.79 \\
$E_{\mathrm{HOMO}-2}$ & -7.54 \\
$E_{\mathrm{LUMO}+2}$ & 0.51 \\
$E_{\mathrm{HOMO}-2}-E_{\mathrm{LUMO}+2}$ gap & 7.03 \\
electronegativity $\chi$ & 4.0530 \\
chemical hardness $\eta$ & 2.1755 \\
softness $\xi-1$ & 0.4596 \\
electrophilicity index $\psi$ & 3.7754 \\
chemical potential $\mu$ & -2.17
\end{tabular}

\subsection{UV-vis spectral analysis}

In order to know the deep insight of electronic transition of PCA molecule, TD-DFT calculations were performed by B3LYP/6-311G(d,p) method. The obtained expansion coefficient $C I$ and electronic values such as absorption wavelength $\lambda$ and oscillator strength $f$ are tabulated in Table IV. The computed absorption maximum value are 293.34, 275.92, and $268.13 \mathrm{~nm}$ in gas phase and $307.62,270.70$, and $263.86 \mathrm{~nm}$ for ethanol phase. We assign absorbance peak 307.62, 270.70, and $263.86 \mathrm{~nm}$ computed by B3LYP/6-311G(d,p) method for ethanol phase as $\pi \rightarrow \pi^{*}$ transition. The same absorption maximum for recorded UV spectrum as 344, 254, and $224 \mathrm{~nm}$. The $\pi \rightarrow \pi^{*}$ transition is expected to occur relatively to lower wavelength due to consequence of extended aromaticity of the ring system [27]. The maximum absorption wavelength corresponding to various electronic transitons are as follows: from $\mathrm{HOMO} \rightarrow \mathrm{LUMO}(99 \%)$, from $\mathrm{HOMO}-1 \rightarrow$ LUMO $(62 \%)$, from $\mathrm{HOMO} \rightarrow \mathrm{LUMO}+1$ $(37 \%)$. The variation of intensity of electronic transition denotes the considerable shift in absorption wavelength. The wavelength are generally reduced as we go from gas to solvent phase.

TABLE IV

Calculated and experimental absorption wavelength, energies and oscillator strengths of PCA using the TD-DFT method at B3LYP $/ 6-311 \mathrm{G}(\mathrm{d}, \mathrm{p})$ method. $M[\%]$ - in solvent major contribution $(\geq 10 \%)$.

\begin{tabular}{|c|c|c|c|c|c|c|c|c|c|}
\hline & \multicolumn{3}{|c|}{ gas phase } & \multirow[t]{2}{*}{ calc. } & \multicolumn{3}{|c|}{ ethanol } & \multicolumn{2}{|c|}{$\overline{\exp .} \pi \rightarrow \pi^{*}$} \\
\hline & $C I$ & $\lambda[\mathrm{nm}]$ & $f$ & & $C I$ & $\lambda[\mathrm{nm}]$ & $f$ & & $M$ \\
\hline \multicolumn{10}{|c|}{ excited state 1} \\
\hline$\overline{43 \rightarrow 44}$ & 0.69584 & 293.24 & 0.6621 & $43 \rightarrow 44$ & 0.70273 & 307.62 & 0.7769 & 344 & $\mathrm{H} \rightarrow \mathrm{L}(99)$ \\
\hline \multicolumn{10}{|c|}{ excited state 2} \\
\hline $41 \rightarrow 44$ & 0.69317 & 275.92 & 0.0000 & $42 \rightarrow 44$ & 0.55562 & 270.70 & 0.0029 & 254 & $\mathrm{H}-1 \rightarrow \mathrm{L}(62)$ \\
\hline $41 \rightarrow 46$ & $-0.12477 \mid$ & & & $43 \rightarrow 45$ & 0.43010 & & & & $\mathrm{H} \rightarrow \mathrm{L}+1$ \\
\hline \multicolumn{10}{|c|}{ excited state 3} \\
\hline $42 \rightarrow 44$ & 0.48370 & 268.13 & 0.0241 & $41 \rightarrow 44$ & 0.69360 & 263.86 & 0.0001 & 224 & $\mathrm{H}-2 \rightarrow \mathrm{L}(96)$ \\
\hline $43 \rightarrow 45$ & 0.50154 & & & $41 \rightarrow 46$ & -0.12349 & & & & \\
\hline
\end{tabular}

\subsection{Thermogravity analysis}

On the basis of the TG method the thermal behaviors like thermal behavior, thermal stability, and thermo gravimetric analysis of the PCA were carried out as shown in Fig. 1. The TG study was performed in the nitrogen atmosphere by heating at the rate of $20^{\circ} \mathrm{C} / \mathrm{min}$ from surrounding temperature to $800^{\circ} \mathrm{C} / \mathrm{min}$ [28]. From thermo gravimetric studies as shown in Fig. 1, it has been found that decomposition takes place in three stages. First step is achieved at $181{ }^{\circ} \mathrm{C}$ accompanied by $56.89 \%$ mass fraction loss, which is attributed to the removal of $\mathrm{OH}$ and second stage decomposition starts at $181^{\circ} \mathrm{C}$ and ends at $266^{\circ} \mathrm{C}$, here the carboxylic acid is decomposed leaving out $41.20 \%$, and the third stage starts at $266^{\circ} \mathrm{C}$ and ends at $422^{\circ} \mathrm{C}$ accompanied with the residue $2.103 \%$. As observed in mass spectrum [29] the peak with 181 mass per atomic number is found to be 100 percent, it signifies that $\mathrm{OH}$ group gets broken from the phenyl ring and then the carboxylic acid is being broken and phenyl acetylene is formed. In this step various acidic fragments are eliminated and residue left out at the end is about $43.31 \%$. The residual carbon mass at the end of the composition reaction is $2.103 \%$. Absence of weight loss around $422{ }^{\circ} \mathrm{C}$ confirms that there is no water of crystallization in the molecular structure. 


\subsection{Molecular docking study}

The docking analysis is used to identify the possibility of protein ligand binding site formation. The structure of the target receptor is gastric cancer (PDBID), brain cancer (PDBID: 1QH4) and lung cancer (PDBID: 2ITO) were obtained from RCSB protein data bank (www.rcsb.org/pdb). Docking study can be done to find the best orientation of ligand with protein. Autodock.2 docking $[30,31]$ software tool is used for docking study. The protein structure was prepared with the help of Autodock Tools graphical user interface. Polar hydrogen was added to the protein and atomic charges were calculated by the Kollman method. The water molecule and co-crystalline liquid were removed. The PCA molecule were prepared for docking by minimizing the energy by B3LYP/6-311G(d,p) method. The active site to the energies was defined to add residues of active side with the use of grid size $80 \times 80 \times 80 \AA^{3}$ using Autogrid [32, 33]. The Lamarckian Genetic Algorithm implemented in Autodock were employed for docking [30]. AutoDock Binding Energy ( $\mathrm{kcal} / \mathrm{mol})$ and inhibition constants $(\mu \mathrm{M})$ were computed and tabulated in Table V. Among the

TABLE V

Molecular docking results of PCA molecule with different types of cancer protein targets. Binding energy $E[\mathrm{kcal} / \mathrm{mol}]$, estimated inhibition constant $K_{i}[\mu \mathrm{M}]$.

\begin{tabular}{c|c|c|c|c}
\hline \hline Protein & Cancer & $E$ & $K_{i}$ & RMSD \\
\hline 1BJ7 & gastric & -4.57 & 445.1 & 7.49 \\
1QH4 & brain & -5.34 & 120.93 & 56.22 \\
2ITO & lung & -6.35 & 22.34 & 54.33
\end{tabular}

TABLE VI

Summary of hydrogen bonding (number $n$, distance $d$ ) of PCA molecule with different types of cancer protein targets.

\begin{tabular}{c|c|c|c}
\hline \hline PDB ID & Bonded residues & $n$ & $d$ \\
\hline \multirow{1}{*}{ 1BJ7 } & protein: A: LYS150:HZ3 & 4 & 2.1 \\
& protein: A: LYS150:HZ3 & & 1.7 \\
& protein: A: ASN147:2HD2 & & 2.5 \\
& protein: A: GLU146:OE1 & & 1.7 \\
& protein: A: ARG36:1HH2 & & 2.0 \\
1QH4 & protein: A: LYS170:HZ3 & 6 & 2.0 \\
& protein: A: LEU165:C & & 2.4 \\
& protein: A: GLY163:O & & 2.8 \\
& protein: A: TYR173:O & & 2.2 \\
& protein: A: LYS172:HZ2 & & 1.8 \\
& protein: A: TYR173:HN & & 1.9 \\
& protein: A: LYS716:HZ3 & 2 & 2.5 \\
& protein: A: LYS728:HZ2 & & 1.8
\end{tabular}

three proteins the lowest free energy at $-6.35 \mathrm{kcal} / \mathrm{mol}$ and most docked inhibitor interaction with ligand within 2ITO binding site are shown in Fig. 5. They exhibit two $\mathrm{C}=\mathrm{O} \ldots \mathrm{H}$ hydrogen bonding with LYS716 and LYS728 with RMSD being 54.33. The computation suggests

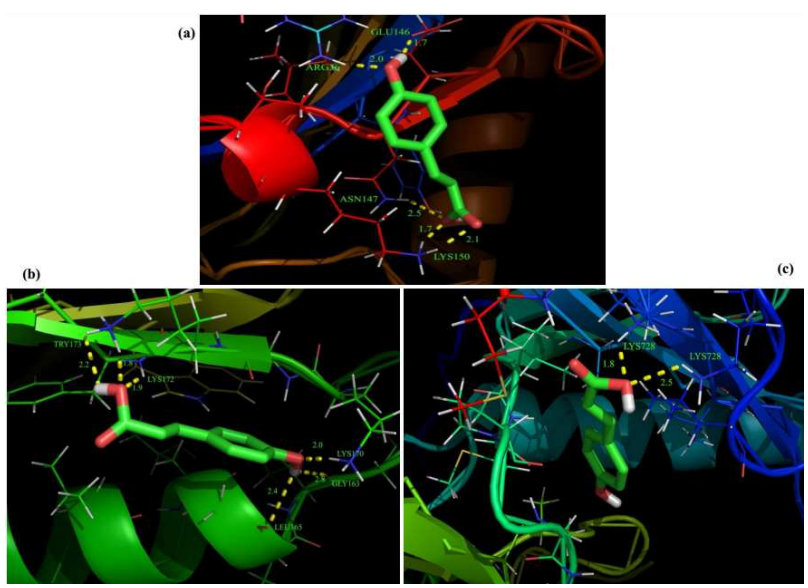

Fig. 5. The hydrogen bond diagram of different target protein (a) 1BJ7, (b) 1QH4, (c) 2ITO with p-coumaric acid molecule.

the $\mathrm{O}-\mathrm{H}$ moiety is engaged in hydrogen bond with amino acid residues of LYS716 and LYS728 as shown in Table VI. By conclusion among the three protein PCA molecule exhibits inhibiting activity against lung cancer. Biological need to be carried out to validate the computational assumptions.

\subsection{Antibacterial effect}

Antimicrobial activity of PCA molecule was performed by Agar well diffusion method and the activity against bacterial pathogens were photographed and shown in Fig. 6. $10 \mathrm{mg}$ of the PCA was screened for its antibacterial activity against Gram positive bacterial

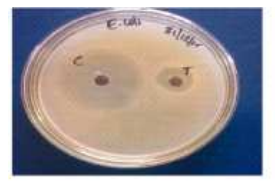

(a)

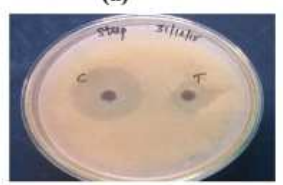

(d)

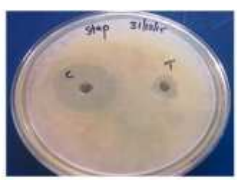

(b)

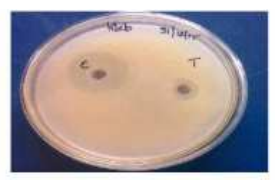

(c)

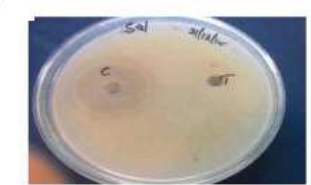

(e)

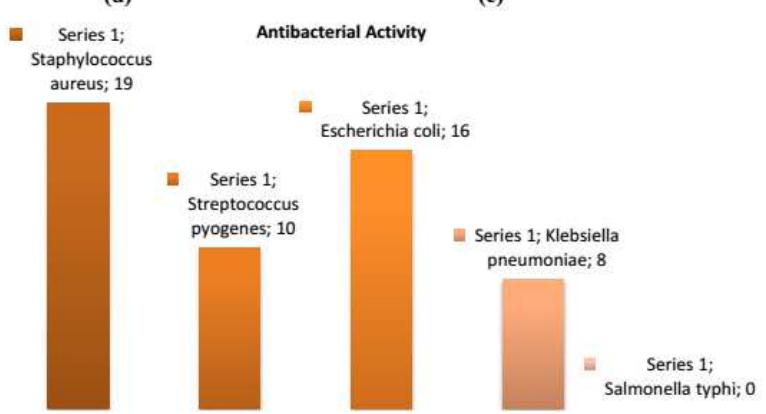

Fig. 6. Antibacterial activity of p-coumaric acid with different bacteria (top) and antimicrobial activities bar diagram (bottom). 
pathogen such as Staphylococcus aureus, Streptococcus pyogenes and Gram negative bacterial pathogens such as Escherichia coli, Klebsiella pneumoniae, Salmonella typhi and Shigella dysentriae etc. with Levofloxacin as control. The results were stimulated in Fig. 6 based on the zone of inhibition $(\mathrm{mm})$ exhibited by the different bacterial strains against PCA which are also shown in Fig. 6. The results were compared with standard antibiotic Levofloxacin with known concentration as control. From the present investigation the compound shows remarkable antibacterial activity against Gram positive and Gram negative bacterial pathogens and the compound expressed high effect against Staphylococcus aureus and Escherichia coli and moderate effect on Streptococcus pyogenes and Klebsiella pneumoniae which are normal inhabitants of human as well as animal origin. The compound has no effect on Salmonella typhi which was a human pathogen found only during diseased condition like typhoid.

\section{Conclusion}

The DFT study on PCA molecule had been perfomed for the first time. In conformational study the most stable conformer is identified as $\mathrm{C} 2$ by finding the lowest conformer energy when compared to other conformers. The optimized monomer structure of $\mathrm{C} 2$ is compared with dimer structure, the geometrical parameters are also elaborately discussed. The deviation of regular hexagonal structure reveals that the ring systems is not uniform, it is concluded that hybridization is possible in the outermost orbitals of substitutional group. The strong hydrogen bond interaction between O19-H20. . O36 and O37-H38...O18 is $\leq 3$ Awhich provide the proof for formation of hydrogen bond. Predicted electronic absorption spectra by TD-DFT calculation with recorded $\mathrm{UV}$-vis spectrum are mainly derived from contribution of $n \rightarrow \pi^{a s t}$ which is also evident from NBO analysis. The energy values of HOMO-LUMO energy gap explain the eventual charge transfer interaction taking place in the molecule. The thermo gravity analysis brings out that at $181^{\circ} \mathrm{C}$ the $\mathrm{OH}$ group gets broken with $56.89 \%$ and at $266^{\circ} \mathrm{C}$ carbonyl group is being decomposed with $41.20 \%$. Molecular docking studies explains the binding energy of PCA molecule with different target cancer protein. The hydrogen bond distance between PCA with various amino acids of the protein binding sites signifies the bioactivity of the molecule. Antimicrobial activity analysis suggest that PCA molecule has excellent antimicrobial activity nature against Staphylococcus aureus and Escherichia coli and moderate effect on Streptococcus pyogenes and Klebsiella pneumoniae which are normal inhabitants of human as well as animal origin.

\section{Acknowledgments}

We remain grateful to the Administration of St. Joseph's College of Arts and Science (Autonomous), Cud- dalore for providing the Quantum Computational Research Lab at the Department of the Physics for all the computational works of the compound. We acknowledge Mr. D. Jayarajan, Head, Department of Microbiology, Divine Mother College, Korkadu, Puducherry, for his valuable support in antimicrobial studies.

\section{References}

[1] A. Svobodova, J. Psotova, D. Walterova, Biomed. Pap. 147, 137 (2003).

[2] C. Alasalvar, J.M. Gregor, D. Hang, P.C. Quantick, F. Shahidi, J. Agric. Food Chem. 49, 1410 (2001).

[3] F. Shahidi, C.A. Chandrasekara, Phytochem. Rev. 9, 147 (2010).

[4] M. Kalinowska, B. Laderiere, P. Champagne, M.K. Sadowy, W. Lewandowski, Spectrochim. Acta A 103, 264 (2013).

[5] L.R. Ferguson, S.T. Zhu, P.J. Harris, Mol. Nutr. Food Res. 49, 585 (2005).

[6] K. Kikugawa, T. Hakamada, M. Hasunuma, T. Kurechi, J. Agric. Food Chem. 3, 780 (1983).

[7] N. Ravikumar, G. Gaddamanugu, K.A. Solomon, J. Mol. Struct. 1033, 272 (2013).

[8] M.K. Sadowy, R. Swislocka, H. Lewandowska, J. Piekut, W. Lewandowski, Molecules 13, 3146 (2015).

[9] N. Kumar, V. Pruthi, N. Goel, J. Mol. Struct. 1085, 242 (2015).

[10] V. Arjunan, R. Anitha, M.K. Marchewka, S. Mohan, Haifeng Yang, J. Mol. Struct. 1080, 122 (2015).

[11] A. Garzón, I. Bravo, A.J. Barbero, J. Albaladejo, J. Agric. Food Chem. 62, 9705 (2014).

[12] C. Giacomelli, F.S. Miranda, N.S. Goncalves, A. Spinelli, Redox Rep. 9, 263 (2004).

[13] M.J. Frisch, G.W. Trucks, H.B. Schlegel, G.E. Suzerain, M.A. Robb, J.R. Cheeseman Jr., J.A. Montgomery, T. Vreven, K.N. Kudin, J.C. Burant, J.M. Millam, S.S. Iyengar, J. Tomasi, V. Barone, B. Mennucci, M. Cossi, G. Scalmani, N. Rega, G.A. Petersson, H. Nakatsuji, M. Hada, M. Ehara, K. Toyota, R. Fukuda, J. Hasegawa, M. Ishida, T. Nakajima, Y. Honda, O. Kitao, H. Nakai, M. Klene, X. Li, J.E. Knox, H.P. Hratchian, J.B. Cross, V. Bakken, C. Adamo, J. Jaramillo, R. Gomperts, R.E. Stratmann, O. Yazyev, A.J. Austin, R. Cammi, C. Pomelli, J.W. Ochterski, P.Y. Ayala, K. Morokuma, G.A. Voth, P. Salvador, J.J. Dannenberg, V.G. Zakrzewski, S. Dapprich, A.D. Daniels, M.C. Strain, O. Farkas, D.K. Malick, A.D. Rabuck, K. Raghavachari, J.B. Foresman, J.V. Ortiz, Q. Cui, A.G. Baboul, S. Clifford, J. Cioslowski, B. Stefanov, G. Liu, A. Liashenko, P. Piskorz, I. Komaromi, R.L. Martin, D.J. Fox, T. Keith, M.A. AlLaham, C.Y. Peng, A. Nanayakkara, M. Challacombe, P.M.W. Gill, B. Johnson, W. Chen, M.W. Wong, C. Gonzalez, J.A. Pople, Gaussian 09, Gaussian Inc., Pittsburgh 2003.

[14] G.A. Petersson, M.A. Allaham, J. Chem. Phys. 94, 6081 (1991).

[15] G.A. Petersson, A. Bennett, T.G. Tensfeldt, M.A. Allaham, W.A. Shirley, J. Mantzaris, J. Chem. Phys. 89, 2193 (1988). 
[16] M. Szafran, A. Komasa, E.B. Adamska, J. Mol. Struct. Theochem. 827, 101 (2007).

[17] C. James, A. Amal Raj, R. Reghunathan, I. Hubert Joe, V.S. Jayakumar, J. Raman Spectrosc. 37, 1381 (2006).

[18] S. Raghunathan, V. Pattabhi, Acta Crystallogr. B 35, 214 (1979).

[19] S. Raghunathan, V. Pattabhi, Acta Crystallogr. B 37, 1299 (1981).

[20] K. Fukui, Science 218, 474 (1982).

[21] S. Gunasekaran, R.A. Balaji, S. Kumaran, G. Anand, S. Srinivasan, Can. J. Anal. Sci. Spectrosc. 53, 149 (2008).

[22] N.M. O'Boyle, A.L.T. Tenderhole, K.M. Langer, J. Comp. Chem. 29, 839 (2008).

[23] Y. Sheena Mary, H.T. Varghese, C.Y. Panicker, T. Thieman, A.A.Al. Saddi, S.A. Po Poola, C.V. Alsenoy, Y.A. Jasem, Spectrochim. Acta A 150, 533 (2015).

[24] T.A. Koopmans, Physica 1, 104 (1934).
[25] R.J. Parr, R.G. Person, J. Am. Chem. Soc. 105, 7152 (1983)

[26] A. Urbaniak, M. Szela, M. Molski, Comput. Theor. Chem. 1012, 33 (2013).

[27] M. Govindharajan, K. Ganesan, S. Periandy, M. Karaback, Spectrochim. Acta A Mol. Biomol. Spectr. 79, 646 (2010).

[28] S. Xavier, S. Periandy, K. Carthigayan, S. Sebastian, J. Mol. Struct. 1125, 204 (2016).

[29] SDBS Web: National Insitute of Advanced Industrial Science and Technology, 18.7.2016.

[30] G.M. Morris, R. Huey, W. Lindstrom, J. Comput. Chem. 30, 2785 (2009)

[31] G.M. Morris, R. Huey, A.J. Olson, Curr. Protoc. Bioinf. 23, 13514 (2007)

[32] M.M. Garrett, S.G. David, S.H. Robert, H. Ruth, E.H. William, K.B. Richard, J.O. Arthur, J. Comput. Chem. 19, 1639 (1998).

[33] H. Ruth, M.M. Garrett, J.O. Arthur, S.G. David, J. Comput. Chem. 28, 1145 (2007). 